九州大学学術情報リポジトリ

Kyushu University Institutional Repository

Life support techniques related to survival after out-of-hospital cardiac arrest in infants

安部，猛

Graduate School of Medical Sciences, Kyushu University

https://doi.org/10.15017/24722

出版情報: 九州大学，2012，博士（医学），課程博士

バージョン：

権利関係: (C) 2012 Elsevier Ireland Ltd. 


\title{
Life support techniques related to survival after out-of-hospital cardiac arrest in infants
}

\begin{abstract}
[197/250]
Aim of the study: The incidence rate of out-of-hospital cardiac arrest (OHCA) among infants is high; however, little is known about effective life-support for this group. Thus, we examined factors related to 1-month survival after OHCA among infants.

Methods: All infant OHCA cases occurring between 2005 and 2008 in Japan were extracted from the National Utstein Registry. Split-half random sampling and signal detection analysis were used to identify the effective factors on1-month survival after
\end{abstract} OHCA.

Results: The mutual interaction of life support techniques and other factors were identified and used to divide the study population into five subgroups. A witness to the cardiac arrest, rescue breathing administered by a bystander, and less than 18 min to hospital arrival or a witness to the arrest, no rescue breathing and less than $7 \mathrm{~min}$ for the ambulance to arrive at the scene were found to be related to higher survival after OHCA in infants. The survival proportions for these subgroups were $44.83 \%$ (95\% CI:

25.58-64.08) and 19.18\% (95\% CI: 14.64-23.72), respectively.

Conclusion: The probability of survival after OHCA in infants may be improved by a bystander witnessing the arrest and providing the rescue breathing at the first sight of 
arrest. 


\section{Introduction}

The incidence of out-of-hospital cardiac arrest (OHCA) among infants (i.e.,

$<1$ year of age) was 65.9 per 100,000 person-years in Japan; the 1-month survival proportion is $7.0 \% .{ }^{1}$ Possible causes of OHCA among children 0-4 years of age include asphyxia from drowning or sudden infant death syndrome (SIDS), trauma, and drug intoxication, among others. ${ }^{2-4}$ Among these causes, asphyxia has been shown to be a leading cause of OHCA among infants. ${ }^{3,5}$ Recently, it has been reported that while OHCA with cardiac origins does occur in infants; ${ }^{3,6,7}$ the cause of two-thirds of infant OHCA cases remains unknown. ${ }^{2}$ Thus, we considered all possible causes of infant OHCA together.

Rescue breathing and chest compressions have been shown to be effective life support techniques for adults and children in cardiac arrest resulting from asphyxia. ${ }^{8-10}$ However, the American Heart Association (AHA) guidelines indicate that little evidence exists to support the efficacy of paediatric basic life support (PBLS) and paediatric advanced life support (PALS) for infants during their first 12 months of life, ${ }^{11,12}$ and other findings on life support factors related to paediatric OHCA are inconsistent. ${ }^{13}$ In addition, a caregiver is the most likely person to observe an infant experiencing OHCA $;{ }^{14}$ however, it is unknown whether the observation of the event by a caregiver is 
related to the infant's survival.

Thus, little is known about life support following OHCA in infants. Multiple causal factors coexist in all OHCA cases, and the probability of survival after OHCA varied according to the degree of overlap among these factors. A quantitative evaluation of the probability of survival after OHCA according to the degree of overlap will be useful for saving lives in emergency situations. However, the effect of a caregiver's observation, PBLS by a bystander, or PALS on the outcome of OHCA in infants in a large population study is limited. Thus, the present study performed an exploratory approach to analyse the Japanese Utstein-style national database to identify factors affecting the outcome in infants following OHCA. The purpose of our study was two-fold: (1) to reveal how the combination of multiple factors increased or decreased the probability of 1-month survival following OHCA in infants, and (2) to determine whether a bystander witnessing the event was related to the probability of 1-month survival following OHCA in infants. These results will increase the effectiveness of PBLS by a bystander and PALS and improve these procedures.

\section{Methods}

Study design and population 
The National Utstein Registry of the Fire and Disaster Management Agency

(FDMA) of Japan is a nationwide, population-based, prospective registry of

OHCA. ${ }^{1,15-18}$ The present observational study enrolled all infant OHCA cases between January 1, 2005 and December 31, 2008 in Japan. Thus, all infants less than 1 year of age who had an OHCA, received emergency life support care, and were transported to a medical institution during the study period are included. A detailed description of the Japanese Utstein Registry has been published elsewhere. ${ }^{1,15-18}$ The FDMA supplied the anonymous data, and the requirement of written informed consent was waived. The ethics committee of Kyushu University Graduate School of Medical Sciences approved the present study.

\section{Outcome and predictors}

The outcome variable was 1-month survival after OHCA in infants recorded by the emergency care providers in charge. Explanatory variables were categorised into three groups: clinical and transport, PBLS by a bystander, and PALS information. The clinical and transport information included patient gender, the presence of an emergency life-saving technician in the ambulance, the presence of a medical doctor in the ambulance, time from emergency call to ambulance arrival on the scene, time from 
emergency call to hospital arrival, and initial electrocardiogram (ECG) waveform. The PBLS by a bystander information included eyewitness observation of the cardiac arrest, type of bystander, chest compressions performed by the bystander, rescue breathing performed by the bystander, and AED use by the bystander. PBLS by emergency medical personnel information included chest compressions and rescue breathing but were not documented due to a national consensus. Thus, information regarding PBLS by emergency medical personnel was surrogated by time to ambulance arrival, as described above. PALS information included defibrillation by emergency medical personnel, advanced airway device use, obtaining intravenous access, and epinephrine injection. In addition, return of spontaneous circulation (ROSC) before hospital arrival can also be used as an outcome measure. However, because the purpose of the study was to identify the life-support factors related to one-month survival, ROSC was not entered into the exploratory analysis in the study. Instead, the prevalence of ROSC in the subgroups was calculated because of the prevalence's usefulness in the interpretation of the results. Cases with missing data for age and other variables were excluded from further analyses. 
Descriptive analyses using the entire sample were conducted first, and $t$-tests or tests of independence were used to compare survival versus non-survival. Next, the population data were randomly divided into two samples: one for a prediction analysis (sample 1, $n=1,595$ ) and one for a validation analysis (sample $2, n=1,594)$. The randomisation was performed using the SPSS software (ver. 19; SPSS, Chicago, IL, USA).

Signal detection analysis (SDA) (ROC 5.0 software $^{19}$ ) was performed on sample 1 to identify factors related to the 1 -month survival proportion. SDA is known as a repetitive partitioning and nonparametric process and assesses combinations of independent variables that are categorised into two subgroups according to a selected criterion, such as a dichotomous variable or a certain cut-off point for a continuous variable. The subgroups identified are mutually exclusive, maximally discriminating subgroups for a dichotomous outcome. SDA is appropriately and ideally suited for an exploratory analysis, particularly when the need to measure higher-order interactions among independent variables is anticipated because of clinical evidence. Thus, linearity and normality in residuals from the model's equation or multicolinearity among independent variables, as in a multivariate analysis, are not needed for consideration. ${ }^{20-24}$ The SDA partitioning process identifies unknown combinations of certain independent variables to maximise both sensitivity and specificity in predicting 
patient survival. This optimally efficient variable or cut-off point is determined by the maximum weighted-kappa coefficient..$^{20-24}$ After selecting the first variable, the program will repeat partitioning for each subgroup using all of the independent variables until the stopping-rules are applied. The stopping-rules for the partitioning processes were triggered when (1) < 10 patients appeared in a subgroup, (2) no variable was found with a significance level $p<0.05$, and $(3) \leq 0$ values were in the lower limits of the $95 \%$ confidence interval of the maximum weighted-kappa coefficient, obtained using one of the bootstrap methods (Jack-knife method). ${ }^{20-24}$

The Cochran-Mantel-Haenszel test was performed to compare the survival proportion between the prediction and validation samples, stratified by the subgroups. $^{25,26}$ The validation sample (sample 2) was categorised into mutually exclusive subgroups based on the information from the SDA in the prediction sample (sample 1). The split-sample will be validated if no significant difference in the survival proportion is found between samples 1 and $2 .^{25,26}$ To verify the adequacy of the results obtained from the SDA, we entered the combination terms into a logistic regression model and constructed a hierarchically well-formulated model (HWF). ${ }^{27,28}$ Subsequently, we followed the hierarchy principle, ${ }^{29}$ and fitted the model within the framework of a hierarchical backward elimination approach. 
Using all of the samples, the subgroups were compared according to the study variables listed in Table 1. Analysis of variance (ANOVA) procedures for continuous variables and tests of independence for dichotomous or discrete variables were used. Two-tailed $p$-values $<0.05$ were deemed to indicate statistical significance. Analyses were conducted using the SPSS software (ver. 19; SPSS, Chicago, IL, USA).

\section{Results}

Out of 3,350 infant OHCA cases, 3,189 (95.19\%) were used in the present analysis, and the remaining cases were excluded according to the selection criteria (Fig. 1). The descriptive characteristics of the study population are shown in Table 1. Overall, 8.3\% of the individuals survived. The number of OHCA incidences per year and the 1-month survival proportion between 2005 and 2008 were $n=623$ and 8.35\% in 2005, $n=622$ and $8.36 \%$ in 2006, $n=859$ and $7.92 \%$ in 2007, and $n=1,085$ and $8.48 \%$ in 2008. The chi-squared analysis revealed no difference in the annual survival proportions during the study period $\left(\chi^{2}=0.22, p=0.9751\right)$.

As shown in Figure 2, the survival proportion was 8.8\% in the prediction sample. The SDA identified five distinct subgroups. The subgroups were numbered in descending order of survival proportion. Subgroup 1 with a $60 \%$ survival proportion 
was characterised as having a bystander observe the OHCA, receiving bystander rescue breathing, and arriving at the hospital in less than $18 \mathrm{~min}$. Subgroup 2 with a 24\% survival proportion was characterised as having a bystander observe the OHCA, receiving bystander rescue breathing, and arriving at the hospital after $18 \mathrm{~min}$ or longer. Subgroup 3 with a $20 \%$ survival proportion was characterised as having a bystander observe the OHCA, receiving no rescue breathing from a bystander, and waiting less than 7 min for the ambulance to arrive. Subgroup 4 with a 10\% survival proportion was characterised as having a bystander observe the OHCA, receiving no rescue breathing from a bystander, and waiting 7 min or longer for the ambulance to arrive. Subgroup 5 with a $6 \%$ survival proportion was characterised as having no witness to the OHCA. No significant difference in the survival proportion was observed between samples 1 and 2 (Cochran-Mantel-Haenszel test, $\chi^{2}=0.68, p=0.4096$ ). Table 2 shows the final logistic regression model identified within the framework of a backward-elimination approach. Of the four variables identified by the SDA, three (eye witness, rescue breathing by a bystander, and hospital arrival $<18 \mathrm{~min}$ ) were significant predictors of 1-month survival after OHCA. In addition, an interaction between the remaining variable (scene arrival $<7 \mathrm{~min}$ ) and the strongest factor (eye witness) was significant. Overall, the final logistic regression model was consistent with the results identified by 
the SDA, confirming the adequacy of the analysis.

Table 3 summarises the five subgroups in terms of the initial explanatory

variables. In addition to the characteristics revealed by the SDA, the use of life-support techniques varied significantly among the subgroups; however, none of the technique combinations had the same effect on the survival proportion in the different subgroups.

\section{Discussion}

The present study is the first to use population-based data to investigate factors related to survival after OHCA in infants. The study identified four factors associated with outcome following OHCA in infants: (1) a witness to the OHCA, (2) bystander rescue breathing, (3) hospital arrival time, and (4) ambulance arrival at the scene time. We categorised the total population into five subgroups according to the degree these factors overlapped. The 1-month survival proportion of the subgroups ranged from $5.5 \%$ to 44.8\% (Table 3). Among the subgroups identified by the SDA, infants whose collapse was witnessed by a bystander, who were ventilated by a bystander, and who arrived at a hospital within 17 minutes showed the highest 1-month survival proportion of $44.83 \%$. The present study first identified this subgroup as having a survival proportion that was five times higher (44.83\%) than the mean survival proportion (8.28\%). Infants whose 
collapse from cardiac arrest was not observed had the lowest 1-month survival proportion of $5.51 \%$.

The results of the SDA revealed that rescue breathing by a bystander, rather than chest compressions, was a significant predictor of 1-month survival in the subgroups in which a bystander witnessed the OHCA. Infants are more likely than adults to have a primary respiratory arrest, and it is also difficult to accurately detect a pulse in an infant. ${ }^{2,3}$ Both of these factors would suggest that a number of infant OHCA cases might not be cardiac in origin. This hypothesis could partially explain the doubling of the survival proportion for infants whose OHCA was witnessed by a bystander who administered rescue breathing (29.2\%), compared with those infants whose OHCA was witnessed by a bystander who did not administer rescue breathing (14.8\%) (Fig. 2). Similarly, hospital arrival time and the time it took for the ambulance to arrive at the scene were significant predictors of 1-month survival in the subgroups in which the OHCA was witnessed by a bystander, regardless of whether the infant received rescue breathing (Fig. 2). The findings described above would not have been obtained using a regular linear model that treats independent variables and their interaction terms equally. Thus, the SDA approach to analysing higher order interactions of multiple factors provided more information than would the identification of 
significant predictors of 1-month survival within the framework of a linear model.

OHCA cases witnessed by a bystander who administered rescue breathing (Subgroups 1 and 2) had a 29.2\% 1-month survival proportion, which was twice that of OHCA cases witnessed by a bystander who did not administer rescue breathing (14.8\%; Fig. 2). This finding was consistent with previous reports on the effect on the outcome of a bystander witnessing cardiac arrest and performing CPR. ${ }^{1,30}$

The present study identified several factors that affected the survival proportion following OHCA. First, we found that the survival proportion after OHCA among infants was $8 \%$, similar to the $7 \%$ survival proportion reported in a previous study. ${ }^{1}$ The difference in the survival proportion between the present study and a previous study in $\operatorname{Japan}^{1}$ may be attributed to the difference in the study period (3 years vs. 4 years), especially because the fourth year included more cases than each of the previous three years (1085 vs. 623, 622, and 859). Second, we found that the subgroup with a higher probability of survival after OHCA (Subgroup 1) did not receive PALS at the scene of the OHCA (Table 3). This finding was partly consistent with the findings of previous studies that connected epinephrine infection to high mortality ${ }^{31-33}$ but was inconsistent with other findings that supported the efficacy of PALS. ${ }^{12}$ Although the information was not available for the present study, it is possible that PALS or other medical treatments, 
such as hypothermia, after hospitalisation might affect infant survival after OHCA.

Third, the time it took for the ambulance to arrive at the scene was a significant predictor of survival in infants who were observed in cardiac arrest but who did not receive rescue breathing by a bystander (Table 3). The 7-min cut-off is particularly significant for this variable as a response by emergency care technicians in more than eight minutes was proposed as a rule for termination of resuscitation. ${ }^{34}$ In the AHA guidelines, the rule for the termination of resuscitation applies to a patient without ROSC before hospitalisation. ${ }^{35}$ However, according to the Japanese CPR guidelines, all emergency care technicians should provide CPR. Furthermore, do-not-attempt-resuscitation orders and living wills are not accepted in Japan; thus, emergency care providers are not allowed to terminate or decide to terminate resuscitation. ${ }^{36}$ Thus, our finding of a 7-min cut-off value was similar to the previous finding. Fourth, the time it took to arrive at the hospital was longer in Subgroup 2 versus Subgroup 1. Subgroup 2 differed from the other subgroups because the proportions of having a medical doctor in the ambulance and the performance of PALS were higher (Table 3). However, this level of support was not a significant predictor of survival among the subgroups, and was not found to be effective. Interestingly, the proportions of ROSC among subgroups identified by our analysis exhibited inconsistent 
tendencies with the proportion of survival. ROSC is an outcome after life supports performed at the scene of OHCA and might be a predictor for survival in adult patients. ${ }^{30}$ However, in the present study, $68 \%$ of survived patients had no ROSC before hospitalisation (Table 1). This finding supports the theory that a different aetiologic pattern and likely unrecognised respiratory arrests might be common among infant patients.

Our study has several limitations. First, the National Utstein Registry does not include information concerning in-hospital resuscitation; thus, the validity of our findings may be limited because of the lack of these data. Further studies of infant OHCA using a new registry form that includes information about medical treatments after PALS is necessary to validate the present findings. Second, we identified significant predictors of survival after OHCA in infants, but caution is required in attributing a causal relationship between the predictors and survival proportion. Third, autopsy data were not included in the registry. Given the greater chance that infant deaths would result in an autopsy, inclusion of these data might provide a more comprehensive profile of infant OHCA. Fourth, a lack of information on infants' monthly age may affect the validity of the findings. Neonates (less than 3 months of age) may have been included in our study. Because resuscitation for neonates is 
different from that for older infants, ${ }^{37}$ it would have been desirable to exclude neonates from the analysis in the present study. Fifth, a more typical outcome that is studied is survival to hospital discharge, rather than one-month survival as was used in the present study. However, 1 month survival as an outcome variable has been well-documented previously. ${ }^{1,15-17}$ Using this variable to measure infant OHCA outcome is valid. Lastly, a lack of accurate information on the causes of OHCA may influence the validity of our results. In the Utstein Registry, the cause of cardiac arrest with a cardiac origin is classified into three categories (“presumed cardiac,” “others,” and “not applicable”). Causes of cardiac arrest with a non-cardiac origin are “cerebrovascular,” "respiratory,” “malignancy,” “trauma,” “other noncardiac,” and “unknown”; however, there is not a category for SIDS, which is one of the most common causes of OHCA among infants. Further studies using data stratified by cause are needed to confirm the present findings. However, because it is difficult to specify, especially at the time of providing CPR, a cause and aetiology of the OHCA in infants, ${ }^{2,14}$ it is probable that stratification by cause would not guarantee the validity of the findings.

The National Utstein Registry for all OHCA incidences in Japan has been in use since January 2005. The present study extracted all infant OHCA cases from the National Utstein Registry, and analysed the cases that occurred between 2005 and 2008. 
To improve the reliability of the data and to minimise information bias and misclassification, rather than performing analyses stratified by year, we randomly divided the population into two groups with a 50/50 probability and then implemented an exploratory approach on the first group (sample 1) and a cross-validation on the first and second groups (samples 1 and 2). The survival proportion among the subgroups in samples 1 and 2 showed the same trends; thus, we believe that our rigorous methodology and a reliable dataset strengthen the validity of the present findings. The results of the present study indicate that to improve survival after OHCA in infants, parents or caregivers should provide rescue breathing immediately after witnessing a collapse from cardiac arrest. Finally, FDMA in Japan has held BLS seminars for citizens for the past two decades. ${ }^{38}$ The basic life support findings from this study should be disseminated to the public at these seminars, especially to present parents of infants and future parents.

\section{Conclusions}

In summary, we identified factors related to 1-month survival after OHCA in infants. These factors were a witness of the cardiac arrest, bystander rescue breathing, arrival at the hospital in $<18 \mathrm{~min}$, and $<7 \mathrm{~min}$ for the ambulance to arrive at the scene. 
By combining these variables, the study population was divided into five subgroups.

Our findings suggest that, to improve survival after an infant OHCA, a bystander should provide rescue breathing immediately after witnessing a collapse from cardiac arrest.

Conflict of interest: All authors have no conflict of interest.

Disclaimer: The article contents are solely the responsibility of the authors and do not necessarily represent the official views of the Kyushu University or the Fire and Disaster Management Agency, Ministry of Internal Affairs and Communications. 


\section{References}

1. Kitamura T, Iwami T, Kawamura T, Nagao K, Tanaka H, Nadkarni VM, et al.

Conventional and chest-compression-only cardiopulmonary resuscitation by bystanders for children who have out-of-hospital cardiac arrests: a prospective, nationwide, population-based cohort study. Lancet 2010;375:1347-1354.

2. Atkins DL, Everson-Stewart S, Sears GK, Daya M, Osmond MH, Warden CR, Berg RA, the Resuscitation Outcomes Consortium Investigators. Epidemiology and outcomes from out-of-hospital cardiac arrest in children. Circulation 2009;119:1484-1491.

3. Topjian AA, Nadkarni VM, Berg RA. Cardiopulmonary resuscitation in children. Curr Opin Crit Care 2009;15:203-208.

4. Herlitz J, Svensson L, Engdahl J, Gelberg J, Silfverstolpe J, Wisten A, et al. Characteristics of cardiac arrest and resuscitation by age group: an analysis from the Swedish Cardiac Arrest Registry. Am J Emerg Med 2007;25:1025-1031.

5. Gerein RB, Osmond MH, Stiell IG, Nesbitt LP, Burns S. What are the etiology and epidemiology of out-of-hospital pediatric cardiopulmonary arrest in Ontario, Canada? Acad Emerg Med 2006;13:653-658.

6. López-Herce J, García C, Rodríguez-Núñez A, Domínguez P, Carrillo A, Calvo C, et 
al. Long-term outcome of paediatric cardiorespiratory arrest in Spain. Resuscitation 2005;64:79-85.

7. Moler FW, Meert K, Donaldson AE, Nadkarni V, Brilli RJ, Dalton HJ, et al. In-hospital versus out-of-hospital pediatric cardiac arrest: a multicenter cohort study. Crit Care Med 2009;37:2259-2267.

8. Berg RA, Hilwig RW, Kern KB, Babar I, Ewy G. Simulated mouth-to-mouth ventilation and chest compressions (bystander cardiopulmonary resuscitation) improves outcome in a swine model of prehospital pediatric asphyxia cardiac arrest. Crit Care Med 1999;27:1893-1899.

9. Berg RA, Hilwig RW, Kern KB, Wey GA. "Bystander” chest compressions and assisted ventilation independently improve outcome from piglet asphyxial pulseless “cardiac arrest”. Circulation 2000;101:1743-1748.

10. Topjian AA, Berg RA, Nadkarni VM. Pediatric cardiopulmonary resuscitation: advances in science, techniques, and outcomes. Pediatrics 2008;122:1086-1098.

11. Berg MD, Schexnayder SM, Chameides L, Terry M, Donoghue A, Hickey RW, et al. Part 13: pediatric basic life support: 2010 American Heart Association Guidelines for Cardiopulmonary Resuscitation and Emergency Cardiovascular Care. Circulation 2010;122(suppl 3):S862-S875. 
12. Kleinman ME, Chameides L, Schexnayder SM, Samson RA, Hazinski MF, Atkins DL, et al. Part 14: pediatric advanced life support: 2010 American Heart Association Guidelines for Cardiopulmonary Resuscitation and Emergency Cardiovascular Care. Circulation 2010;122(suppl 3):S876-S908.

13. Donoghue AJ. Nadkarni V, Berg RA, Osmond MH, Wells G, Nesbitt L, et al. Out-of-hospital pediatric cardiac arrest: an epidemiologic review and assessment of current knowledge. Ann Emerg Med 2005;46:512-522.

14. Donohoe RT, Innes J, Gadd S, Whitbread M, Moore F. Out-of-hospital cardiac arrest in patients aged 35 years and under: a 4-year study of frequency and survival in London. Resuscitation 2010;81:36-41.

15. Kitamura T, Iwami T, Kawamura T, Nagao K, Tanaka H, Hiraide A. Nationwide public-access defibrillation in Japan. N Engl J Med 2010;362:994-1004.

16. Iwami T, Nichol G, Hiraide A, Hayashi Y, Nishiuchi T, Kajino K, et al. Continuous improvements in "chain of survival” increased survival after out-of-hospital cardiac arrests: a large-scale population-based study. Circulation 2009;119:728-734.

17. Yasunaga H, Horiguchi H, Tanabe S, Akahane M, Ogawa T, Koike S, et al. Collaborative effects of bystander-initiated cardiopulmonary resuscitation and prehospital advanced cardiac life support by physicians on survival of 
out-of-hospital cardiac arrest: a nationwide population-based observational study.

Critical Care 2010;14:R199.

18. Ogawa T, Akahane M, Koike S, Tanabe S, Mizoguchi T, Imamura T. Outcomes of chest compression only CPR versus conventional CPR conducted by lay people in patients with out of hospital cardiopulmonary arrest witnessed by bystanders: nationwide population based observational study. BMJ 2011;342:c7106. doi: 10.1136/bmj.c7106.

19. The Aging Clinical Research Center. ROC5 software. Stanford University, 2008.

20. Kraemer HC. Evaluating Medical tests: objective and quantitative guidelines. Newbury Park, CA, Sage, 1992.

21. Kraemer HC. Reconsidering the odds ratio as a measure of 2 by2 association in a population. Stat Med 2004;23:257-270.

22. Rodriguez MA, Winkleby MA, Ahn D, Sundquist J, Kraemer HC. Identification of population subgroups of children and adolescents with high asthma prevalence. Arch Pediatr Adolesc Med 2002;156:269-275.

23. James KE, White RF, Kraemer HC. Repeated split sample validation to assess logistic regression and recursive partitioning: an application to the prediction of cognitive impairment. Stat Med 2005;24:3019-3035. 
24. Kiernan M, Kraemer HC, Winkleby MA, King AC, Taylor CB. Do logistic regression and signal detection identify different subgroups at risk?: implications for the design of tailored interventions. Psychol Methods 2001;6:35-48.

25. Atienza AA, Yaroch AL, Mãsse LC, Moser RP, Hesse BW, King AC. Identifying sedentary subgroups: the National Cancer Institute’s Health Information National Trends Survey. Am J Prev Med 2006;31:383-390.

26. Hair JFJr, Black WC, Babin BJ, Anderson RE. Multivariate data analysis. 7th ed. Upper Saddle River, NJ, Prentice Hall, 2010.

27. Kleinbaum DG, Klein M, Pryor ER. Logistic regression: a self-learning text. 3rd ed. New York, Springer, 2010.

28. Jaccard J. Interaction effects in logistic regression. Thousand Oaks, CA, Sage, 2001.

29. Bishop YM, Fienberg SE, Holland PW. Discrete multivariate analysis: theory and practice. New York, Springer, 2007.

30. Sasson C, Rodgers MAM, Dahl J, Kellermann AL. Predictors of survival from out-of-hospital cardiac arrest. A systematic review and meta-analysis. Circ Cardiovasc Qual Outcomes 2010;3:63-81.

31. Moler FW, Donaldson AE, Meert K, Brilli RJ, Nadkarni V, Shaffner DH, et al. Multicenter cohort study of out-of-hospital pediatric cardiac arrest. Crit Care Med 
2011;39:1-9.

32. Perondi MBM, Reis AG, Paiva EF, Nadkarni VM, Berg RA. A comparison of high-dose and standard-dose epinephrine in children with cardiac arrest. N Engl J Med 2004;350:1722-1730.

33. Young KD, Gausche-Hill M, McClung CD, Lweis RJ. A prospective, population-based study of the epidemiology and outcome of out-of-hospital pediatric cardiopulmonary arrest. Pediatrics 2004;114:157-164.

34. Morrison LJ, Vistentin LM, Kiss A, Theriault R, Eby D, Vermeulen M, et al. Validation of a rule for termination of resuscitation in out-of-hospital cardiac arrest. N Engl J Med 2006;355:478-487.

35. Morrison LJ, Kierzek G, Diekema DS, Sayre MR, Silvers SM, Idris AH, et al. Part 3: ethics: 2010 American Heart Association Guidelines for Cardiopulmonary Resuscitation and Emergency Cardiovascular Care. Circulation 2010;122(suppl 3):S665-S675.

36. Japanese guidelines for emergency care and cardiopulmonary resuscitation. 3rd ed. Tokyo: Health Shuppansha, 2007. [in Japanese]

37. Kattwinkel J, Perlman JM, Aziz K, Colby C, Fairchild K, Gallagher J, et al. Part 15: neonatal resuscitation: 2010 American Heart Association Guidelines for 
Cardiopulmonary Resuscitation and Emergency Cardiovascular Care. Circulation. 2010;122(suppl 3):S909-S919.

38. Fire and Disaster Management Agency, Ministry of Internal Affairs and Communications. Current State of Emergency and Rescue 2010. [in Japanese] 


\section{Legends to figures}

Fig. 1. Cardiac arrest patients in Japan between $1 / 1 / 2005$ and 12/31/2008 $(n=3,189)$.

Fig. 2. Life support factors related to 1-month survival proportion as identified with the signal detection analysis $(n=1,595)$. 


\begin{tabular}{|c|c|c|c|c|c|c|c|c|}
\hline & & \multicolumn{2}{|c|}{$\begin{array}{l}\text { Total } \\
(n=3,189) \\
\text { frequency }(\%) / \\
\text { mean } \pm \text { SD (range) }\end{array}$} & \multicolumn{2}{|c|}{$\begin{array}{l}1 \text { month-survival } \\
(n=264) \\
\text { frequency }(\%) / \\
\text { mean } \pm \text { SD (range) }\end{array}$} & \multicolumn{3}{|c|}{$\begin{array}{l}\text { Non-survival } \\
(n=2,925) \\
\text { frequency (\%)/ } \\
\text { mean } \pm \text { SD (range) }\end{array}$} \\
\hline \multicolumn{9}{|l|}{ CLINICAL AND TRANSPORT INFORMATION } \\
\hline Gender & Female & 1,334 & (41.83) & 108 & $(40.91)$ & 1,226 & $(41.91)$ & ns \\
\hline Presence of emergency life-saving technician on the ambulance & Yes & 3,003 & $(94.17)$ & 250 & $(94.70)$ & 2,753 & $(94.12)$ & ns \\
\hline Presence of medical doctor on the ambulance & Yes & 125 & $(3.92)$ & 13 & $(4.92)$ & 112 & $(3.83)$ & ns \\
\hline $\begin{array}{l}\text { Time from emergency call to } \\
\text { ambulance arrival on the scene (min) }\end{array}$ & & $6.73 \pm 3.7$ & $(0-48)$ & $6.19 \pm 2.9$ & $(0-28)$ & $6.77 \pm 3.7$ & $(0-48)$ & ** \\
\hline $\begin{array}{l}\text { Time from emergency call to } \\
\text { hospital arrive (min) }\end{array}$ & & $28.57 \pm 16.7$ & $(4-455)$ & $27.83 \pm 20.1$ & $(9-239)$ & $28.64 \pm 16.3$ & $(4-455)$ & ns \\
\hline Initial ECG waveform & VF or pulseless VT & 105 & (3.29) & 24 & $(9.09)$ & 81 & $(2.77)$ & $* * *$ \\
\hline ROSC before hospital arrival & Yes & 126 & $(3.95)$ & 84 & $(31.82)$ & 42 & $(1.44)$ & $* * *$ \\
\hline \multicolumn{9}{|l|}{ PEDIATRIC BASIC LIFE SUPPORT BY BYSTANDER } \\
\hline Eye witness observation of the cardiac arrest & Yes & 759 & $(23.80)$ & 130 & $(49.24)$ & 629 & $(21.50)$ & $* * *$ \\
\hline \multirow[t]{3}{*}{ Type of bystander } & Family member & 486 & $(15.24)$ & 85 & $(32.20)$ & 401 & $(13.71)$ & $* * *$ \\
\hline & Others & 299 & $(9.38)$ & 48 & (18.18) & 251 & $(8.58)$ & \\
\hline & None & 2,404 & (75.38) & 131 & $(49.62)$ & 2,273 & $(77.71)$ & \\
\hline Chest compression performed by bystander & Performed & 1,463 & $(45.88)$ & 124 & $(46.97)$ & 1,339 & $(45.78)$ & ns \\
\hline Rescue breathing performed by bystander & Performed & 998 & $(31.30)$ & 104 & (39.39) & 894 & $(30.56)$ & ** \\
\hline AED use by bystander & Performed & 6 & $(0.19)$ & 4 & $(1.52)$ & 2 & $(0.07)$ & $* * *$ \\
\hline \multicolumn{9}{|l|}{ PEDIATRIC ADVANCED LIFE SUPPORT } \\
\hline Defibrillation by emergency medical personnel & Performed & 75 & $(2.35)$ & 8 & $(3.03)$ & 67 & $(2.29)$ & ns \\
\hline Advanced airway device use & Performed & 455 & (14.27) & 21 & $(7.96)$ & 434 & (14.84) & $* *$ \\
\hline Obtaining intravenous access & Performed & 160 & $(5.02)$ & 2 & $(0.76)$ & 158 & $(5.40)$ & $* * *$ \\
\hline Epinephrine injection & Performed & 55 & (1.73) & 1 & $(0.38)$ & 54 & $(1.85)$ & ns \\
\hline
\end{tabular}

OHCA: out-of-hospital cardiac arrest.; ECG: electrocardiogram; AED: automated external defibrillator; ROSC: return of spontaneous circulation

The $t$-test was performed for continuous variables; Fisher's exact test or chi-square test was performed for the remaining categorical variables when appropriate.

${ }^{*} p<0.05,{ }^{* *} p<0.01,{ }^{* * *} p<0.001$, ns: not significant 
Table 2. Final logistic regression model identified within the framework of hierarchical elimination approach and hierarchy principle

OR $(95 \% C I)$

(A) Eye witness observation of the cardiac arrest

$2.18(1.43-3.33)$

(B) Rescue breathing performed by bystander

$1.58(1.21-2.07)$

(C) Hospital arrival $<18$ min.

$1.53(1.09-2.15)$

(D) Scene arrival $<7$ min.

$0.84(0.59-1.21)$

Interaction terms

$\mathrm{A} \times \mathrm{D}$

$2.56(1.49-4.39)$

Hosmer-Lemeshow test ( $p$ value)

$7.19(p=0.21)$

OR: odds ratio; $C I$ : confidence interval 


\begin{tabular}{|c|c|c|c|c|c|c|}
\hline & $\begin{array}{l}\text { Subgroup } 1 \\
(n=29) \\
\text { Eye witness=Y } \\
\text { Bystander rescue } \\
\text { breathing=Y } \\
\text { Hospital arrival }<18 \\
\end{array}$ & $\begin{array}{l}\text { Subgroup } 2 \\
(n=173) \\
\text { Eye witness }=Y \\
\text { Bystander rescue } \\
\text { breathing=Y } \\
\text { Hospital arrival } \geq 18\end{array}$ & $\begin{array}{l}\text { Subgroup } 3 \\
(n=292) \\
\text { Eye witness=Y } \\
\text { Bystander rescue } \\
\text { breathing=N } \\
\text { Scene arrival<7 }\end{array}$ & $\begin{array}{l}\text { Subgroup } 4 \\
(n=265) \\
\text { Eye witness=Y } \\
\text { Bystander rescue } \\
\text { breathing=N } \\
\text { Scene arrival } \geq 7\end{array}$ & $\begin{array}{l}\text { Subgroup } 5 \\
(n=2,430) \\
\text { Eye witness=N }\end{array}$ & \\
\hline \multicolumn{7}{|l|}{ CLINICAL AND TRANSPORT INFORMATION } \\
\hline Gender (female) & $55.17 \%$ & $40.46 \%$ & $43.84 \%$ & $44.53 \%$ & $41.23 \%$ & $p=0.42$ \\
\hline $\begin{array}{l}\text { Presence of emergency life-saving technician } \\
\text { on the ambulance (yes) }\end{array}$ & $100.00 \%$ & $95.38 \%$ & $93.84 \%$ & $86.42 \%$ & $94.90 \%$ & $p<0.001$ \\
\hline Presence of medical doctor on the ambulance (yes) & $6.96 \%$ & $9.25 \%$ & $5.14 \%$ & $3.02 \%$ & $3.46 \%$ & $p<0.01$ \\
\hline $\begin{array}{l}\text { Time from emergency call to ambulance arrival } \\
\text { on the scene (min.) }\end{array}$ & 4.62 & 7.42 & 4.67 & 9.71 & 6.62 & $p<0.001$ \\
\hline Time from emergency call to hospital arrive (min.) & 14.21 & 32.39 & 29.18 & 36.38 & 27.55 & $p<0.001$ \\
\hline Initial ECG waveform (VF or pulseless VT) & $13.79 \%$ & $7.51 \%$ & $8.90 \%$ & $4.91 \%$ & $2.02 \%$ & $p<0.001$ \\
\hline ROSC before hospital arrival & $16.00 \%$ & $16.11 \%$ & $15.87 \%$ & $4.74 \%$ & $1.93 \%$ & $p<0.001$ \\
\hline \multicolumn{7}{|l|}{ PEDIATRIC BASIC LIFE SUPPORT BY BYSTANDER } \\
\hline Eye witness observation of the cardiac arrest (yes) & $100.00 \%$ & $100.00 \%$ & $100.00 \%$ & $100.00 \%$ & $0.00 \%$ & $p<0.001$ \\
\hline Type of bystander (Family member) & $62.07 \%$ & $69.94 \%$ & $56.16 \%$ & $60.00 \%$ & $0.99 \%$ & $p<0.001$ \\
\hline (Others) & $37.93 \%$ & $30.06 \%$ & $43.84 \%$ & $40.00 \%$ & $0.08 \%$ & \\
\hline Chest compression performed by bystander (yes) & $75.86 \%$ & $79.77 \%$ & $20.55 \%$ & $20.38 \%$ & $48.93 \%$ & $p<0.001$ \\
\hline Rescue breathing performed by bystander (yes) & $100.00 \%$ & $100.00 \%$ & $0.00 \%$ & $0.00 \%$ & $32.76 \%$ & $p<0.001$ \\
\hline AED use by bystander (yes) & $0.00 \%$ & $0.58 \%$ & $0.68 \%$ & $0.38 \%$ & $0.08 \%$ & $p=0.12$ \\
\hline \multicolumn{7}{|l|}{ PEDIATRIC ADVANCED LIFE SUPPORT } \\
\hline Defibrillation by emergency medical personnel (yes) & $0.00 \%$ & $3.47 \%$ & $8.56 \%$ & $4.15 \%$ & $1.36 \%$ & $p<0.001$ \\
\hline Advanced airway device use (yes) & $0.00 \%$ & $13.29 \%$ & $11.30 \%$ & $12.45 \%$ & $15.06 \%$ & $p=0.06$ \\
\hline Obtaining intravenous access (yes) & $0.00 \%$ & $9.25 \%$ & $6.85 \%$ & $5.66 \%$ & $4.49 \%$ & $p<0.05$ \\
\hline Epinephrine injection (yes) & $0.00 \%$ & $5.78 \%$ & $3.08 \%$ & $4.15 \%$ & $1.03 \%$ & $p<0.001$ \\
\hline \multicolumn{7}{|l|}{ OUTCOME } \\
\hline 1 month survival proportion after OHCA & $44.83 \%$ & $21.97 \%$ & $19.18 \%$ & $8.68 \%$ & $5.51 \%$ & $p<0.001$ \\
\hline$(95 \% \mathrm{CI})$ & $(25.58-64.08)$ & $(15.73-28.20)$ & $(14.64-23.72)$ & $(5.27-12.09)$ & $(4.61-6.42)$ & \\
\hline
\end{tabular}

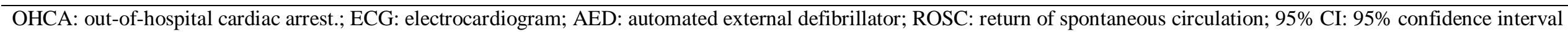
Analysis of variance was performed with continuous variables. The chi-square test was performed for the remaining categorical variables when appropriate. 


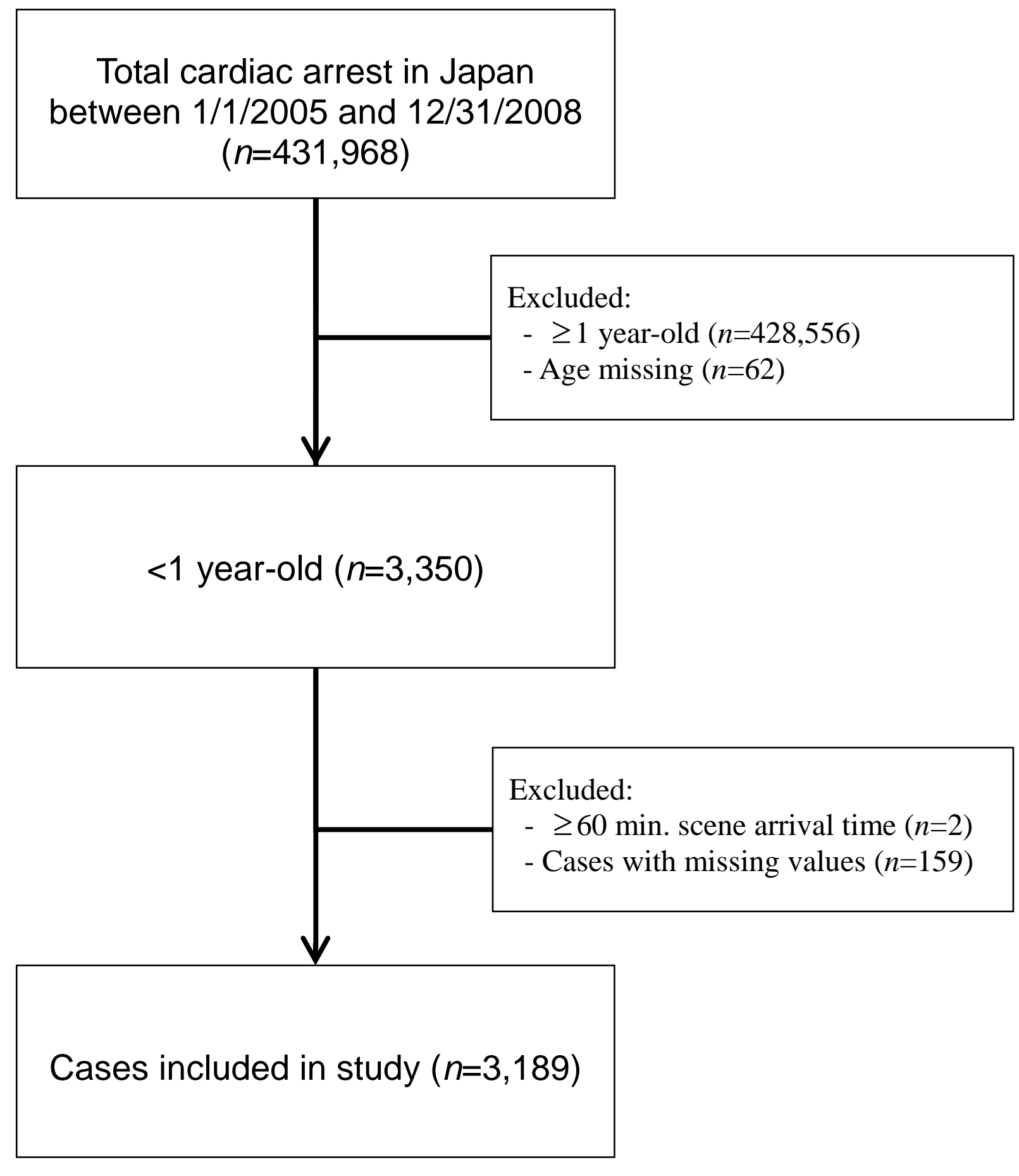

Fig. 1. 


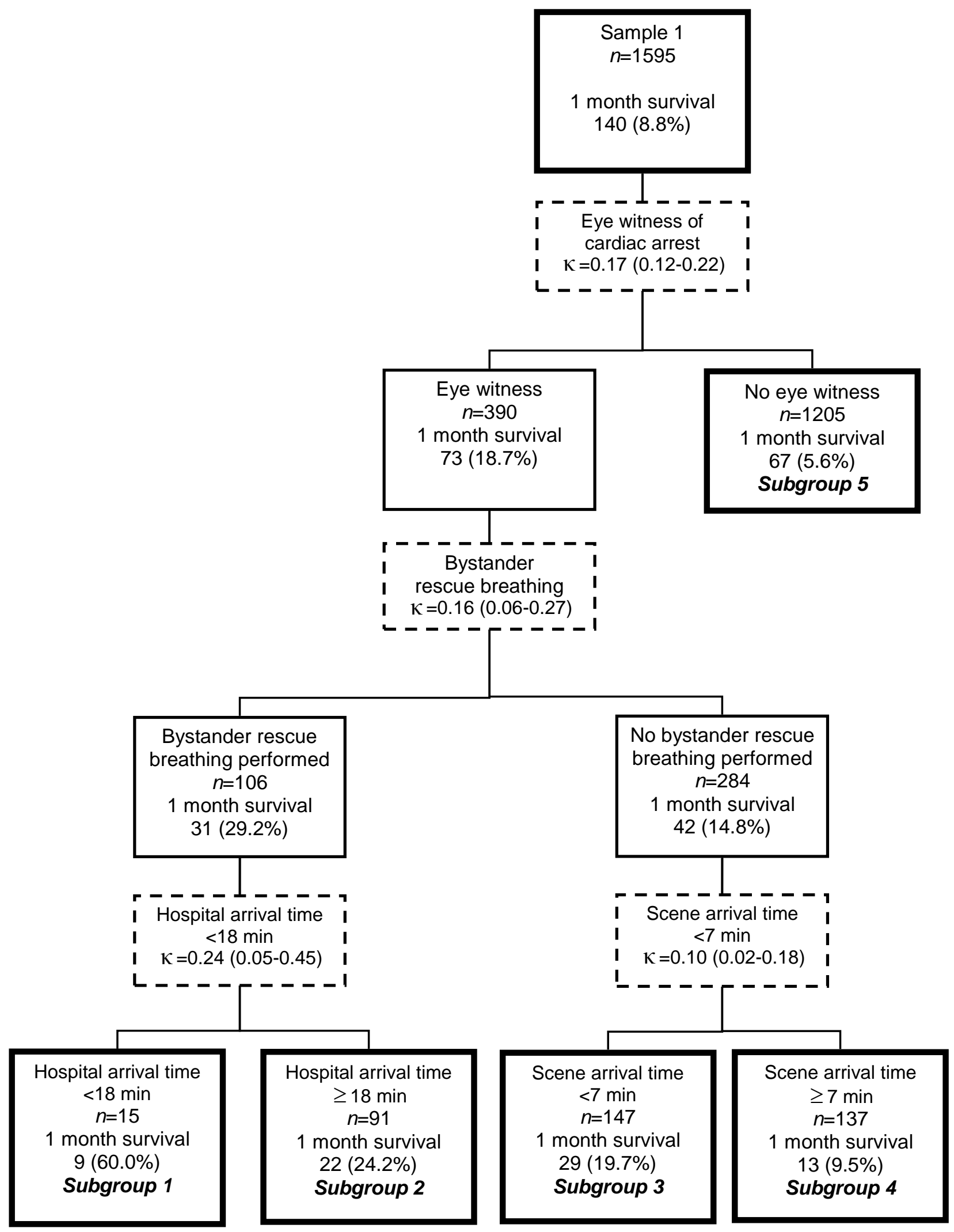

Fig. 2. 